\title{
Effect of Microstructure and Mechanical Properties of CNT/Graphene Reinforced Al- Hybrid MMCs
}

\author{
Bharath Kumar $\mathrm{S}^{1}$, Monish $\mathrm{M}^{2}$, Naveen Kumar B R ${ }^{3}$, Surya Siddanth $\mathrm{P}^{4}$, Anand M N ${ }^{5}$, N Mohan ${ }^{6}$ \\ 1, 2,3,4 UG Students, Department of Mechanical Engineering, Nitte Meenakshi Institute of Technology, Bengaluru \\ ${ }^{5}$ Assistant Professor, Department of Mechanical Engineering, Nitte Meenakshi Institute of Technology, Bengaluru \\ ${ }^{6}$ Professor, Department of Industrial Engineering and Management, Dr. Ambedkar Institute of Technology, Bengaluru
}

\begin{abstract}
In this study, the mechanical properties and microstructure characterization of $\mathrm{CNT} / \mathrm{Graphene}$ reinforced with Aluminium6061 hybrid MMCs. Metal matrix composites are attaining more prominence in the modern day engineering world. It finds very wide applications in various sectors such as defense, aircraft, appliance and sport industry. Aluminium6061 has good strength and is used for manufacturing of variety of components. Powder metallurgy technique is used for fabrication of Al6061-CNT-Graphene hybrid MMCs. The Al6061-CNT-Graphene powder mixtures containing 0.5wt-\% CNT and 0.5, 1 and 1.5 wt-\% Graphene were mixed in a Ball milling for $2 \mathrm{hrs}$ at $200 \mathrm{rpm}$ and is green compacted in a 5 tonne hydraulic press and sintered at $550^{\circ} \mathrm{C}$. The hardness test and compression tests were carried out and Microstructure characterization is done by Optical microscope and Scanning electron microscope. The hybrid composite showcased uniform dispersion of CNT/Graphene and exceptional interfacial bonding with the Aluminium6061. The hardness test and compression test revealed that there is increase in hardness and compression strength of the Hybrid MMCs with percentage wt. increase in graphene.
\end{abstract}

Keywords- Powder Metallurgy, Hybrid MMCs, Aluminium6061, Carbon nano tube, Graphene.

\section{INTRODUCTION}

This Aluminium metal matrix composites (Al-MMCs) are one of the most conventional and very important type of MMCs. They have many applications in automotive, aerospace, sports, electrical and military industries due to high toughness, low density, high specific strength, excellent wear resistance, good thermal stability and controllable expansion coefficient [1]. The development of MMCs has been major breakthrough in materials in the recent decades. $\mathrm{SiC}, \mathrm{Al}_{2} \mathrm{O}_{3}, \mathrm{TiC}, \mathrm{B} 4 \mathrm{C}$, Flyash have been used as ceramic reinforcements by several researchers to reinforce aluminium alloys. [2-7]. In the recent studies Carbon nanotube and graphene are one of the most imperative composite reinforcements. Aluminium 6061 is considered to have high potential for automotive profiles, automotive exterior and very few work have been published.

In the present study powder metallurgy technique has been followed. Powder metallurgy (PM) is used as an alternative to the conventional production processes (machining, cold / hot forming, casting...) because of the superior economical advantages and this done by the application of net shape processing. The raw material utilization is maximum in the PM process. In powder metallurgy process the materials can be blended easily to the exact proportion. The literature survey about the Al-alloy and their composites are as follows.

Ishtiaq Ahmed et al. [8] studied on analysis of Aluminium 6063, CNT and Graphite (Hybrid) Nano Composites by using powder metallurgy. The results revealed that there is significant increase in hardness value of the fabricated composites. Hardness increases with the increase in graphite reinforcement. There was uniform dispersion of graphite and excellent interfacial bonding in the aluminium matrix.

Ming-Jen Tan et al. [9] studied on mixing of CNT and Aluminium powder metal composite. This work studied the mechanical mixing methods, viz. high energy and low energy ball millings, and compared them to a novel polyester binderassisted (PBA) mixing method. Small addition of CNTs $(0.5$ wt.\%) evidently improved the tensile strength and hardness of the composite by comparing with the $\mathrm{Al}$ matrix.

Jie Teng et al. [10] studied on mechanical properties OG Graphene/Aluminium powder metal composite the mechanical properties of the composites were studied using microhardness and tensile tests. Compared to the pure $\mathrm{Al}$ alloy, the graphene/Al composites showed increased strength and hardness.

Anthony Xavior et al. [11] studied on Tribological studies on AA2024-Graphene/CNT nanocomposite processed through powder metallurgy. The results revealed that Graphene/CNT experienced high compressive loads during ball milling. There was improvement in hardness of AA2024 composite as grapheme exhibited more refinement compared to CNT.

\section{MATERIALS AND METHODOLOGY}

\section{A. Composite material fabrication}

Aluminum alloy A6061 was used as matrix material and Graphene/CNT particles were used for the reinforcement materials. Some of the properties of matrix and reinforcement material are given in the tables below. Three types of hybrid composites were fabricated by means of permanent mould powder metallurgy route. Al6061 alloy is also cast for comparison purpose. The mechanical properties of Al6061, designation of the alloy and composites is given in Table 2 and Table 4 respectively.

Table 1: Chemical Composition of A6061

\begin{tabular}{|l|l|}
\hline \multicolumn{2}{|c|}{ Table 1: Chemical Composition of A6061 } \\
\hline Element & Content (\%) \\
\hline Aluminium & 97.9 \\
\hline Magnesium, Mg & 1 \\
\hline
\end{tabular}




\begin{tabular}{|l|l|}
\hline Silicon, $\mathrm{Si}$ & 0.60 \\
\hline Copper, $\mathrm{Cu}$ & 0.28 \\
\hline Chromium, $\mathrm{Cr}$ & 0.20 \\
\hline
\end{tabular}

Table 2: Properties of Al6061

\begin{tabular}{|l|l|}
\hline Properties & Values \\
\hline Density & $2.7 \mathrm{~g} / \mathrm{cc}$ \\
\hline Melting point & $582-652{ }^{\circ} \mathrm{C}$ \\
\hline Elastic modulus & $68.9 \mathrm{GPa}$ \\
\hline Poisson ratio & 0.33 \\
\hline
\end{tabular}

Table 3: Properties of Graphene

\begin{tabular}{|l|l|}
\hline Properties & Values \\
\hline Density & $2.267 \mathrm{~g} / \mathrm{cc}$ \\
\hline Melting point & $3652{ }^{\circ} \mathrm{C}$ \\
\hline Elastic modulus & $2.4 \mathrm{TPa}$ \\
\hline Poisson ratio & 0.456 \\
\hline
\end{tabular}

Table 4: Properties of Carbon-nano-tube (CNT)

\begin{tabular}{|l|l|}
\hline Properties & Values \\
\hline Density & $1.6 \mathrm{~g} / \mathrm{cc}$ \\
\hline Melting point & $3550^{\circ} \mathrm{C}$ \\
\hline Elastic modulus & $1 \mathrm{TPa}$ \\
\hline Poisson ratio & 0.11 \\
\hline
\end{tabular}

Table 5: Designation of Alumina Reinforced Alloy

\begin{tabular}{|c|l|c|}
\hline S/No & Alloy/Composite & Designation \\
\hline 1 & As-Cast 6061 & A6061 \\
\hline 2 & Al6061 $+0.5 \% \mathrm{CNT}+0.5 \%$ Graphene & A1 \\
\hline 3 & Al6061 $+0.5 \% \mathrm{CNT}+1 \%$ Graphene & A2 \\
\hline 4 & $\mathrm{~A} 16061+0.5 \% \mathrm{CNT}+1.5 \%$ Graphene & $\mathrm{A} 3$ \\
\hline
\end{tabular}

Powder metallurgy route was used to fabricate the composites The composite developed by this study will contain varying percentage composition of Graphene $(0.5,1$, and 1.5 weight Percentage) and constant CNT composition(0.5 weight percentage). The aim of the experiment is to study the effect of variation of the percentage composition of AlGraphene/CNT Hybrid composite to predict the mechanical properties and corrosion studies of MMCs and comparing the result with as cast pure Aluminium.

\section{EXPERIMENTS}

Aluminium 6061, Graphene, Carbon nano tube were procured from Mepco (metal powder company). Chemical analysis and purity of the powders were as reported by the suppliers greater than $92 \%$. The powder metallurgy process were carried out in Dr. V. B. Ceramic research centre, Chennai.

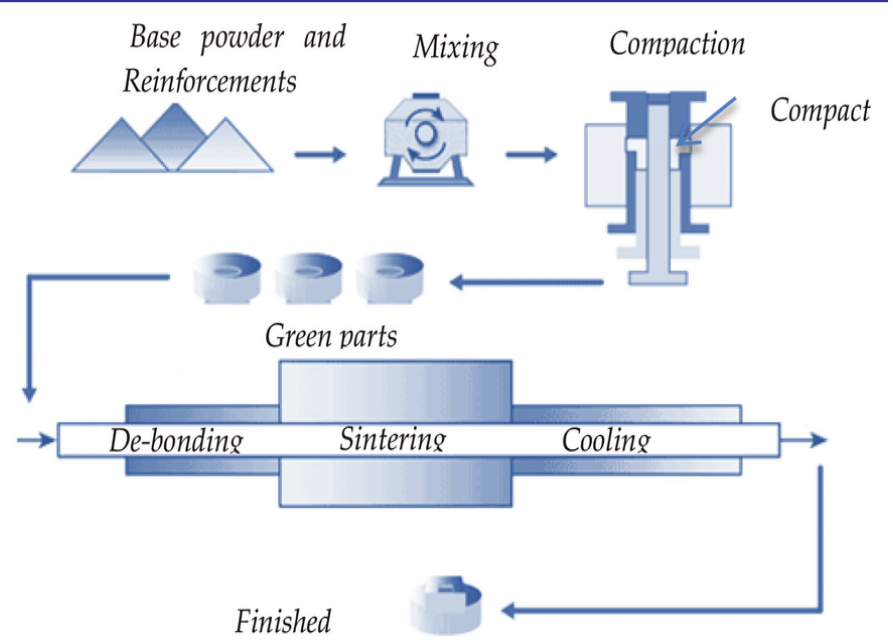

Fig 01: Conventional powder metallurgy process

The powder mixture is made by adding poly vinyl alcohol as binder. The powder mixture is ball milled for $2 \mathrm{hrs}$ at 200 rpm. The green compacts were prepared using 10 tonne uniaxial hydraulic press in a stainless-steel die. The green compacts were sintered at $550^{\circ} \mathrm{C}$ for $2 \mathrm{hrs}$ in nitrogen atmosphere using a tubular furnace and then heat source is put off. The specimens are furnace cooled till room temperature is achieved.

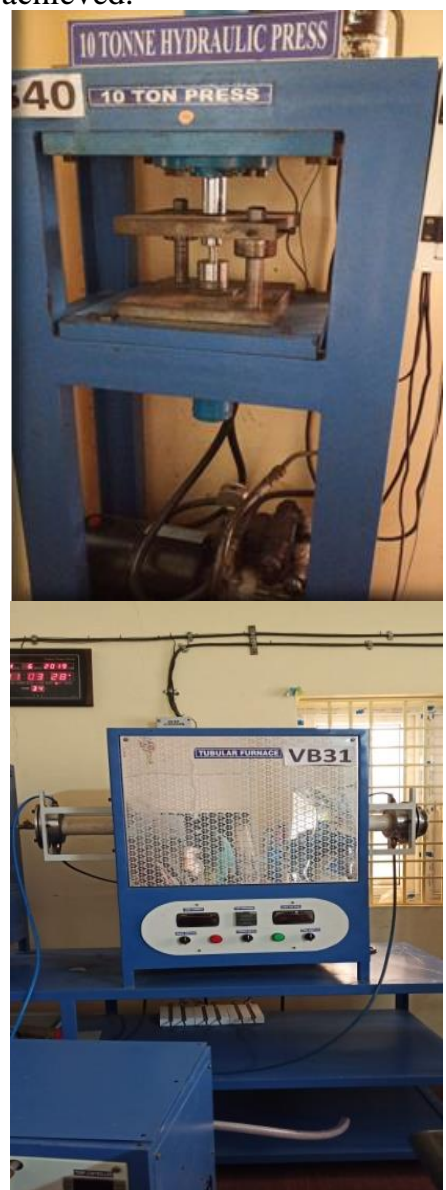

Fig 02: Uni-axial hydraulic press(10 tonne) and Tubular furnace

The hardness test, compression test, and microstructure characterization using SEM and optical microscope were done on the specimens. The hardness test was done using Brinell hardness tester, $250 \mathrm{~kg}$ load was applied on the specimen. 
Hardness is a measure of how safe strong issue is to different sorts of lasting shape change when a compressive power is connected. A few materials (e.g. metals) are harder than others (e.g. plastics). The compression test was performed to determine the compression strength off the specimen. Hardness Test and compression test were done in Nitte Meenakshi Institute of technology, Bangalore.

SEM (Scanning electron microscope) is a form of electron microscope in which a focused beam of electrons are used to scan the surfaces which produces the image of the sample. The beam of electrons interacts with the atoms which are present in the sample which thereby produces various signals that comprises information about the surface texture and the various composition of the sample. SEM available at B.M.S college of Engineering, Bangalore was used for characterization of powders for particle size and shape.

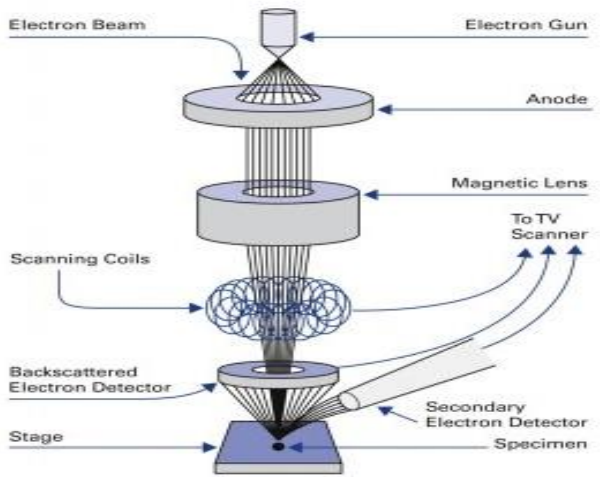

Fig 03: Scanning electron microscope

The optical microscope is also known as light microscope, It is a kind of microscope which commonly utilizes visible light and a system of lenses to create magnified images of very small objects. The basic principle of optical microscope for operating is comparatively simple. An objective lens of optical microscope is alike a very strong magnifying glass. The specimen is placed on the platform and seen through the lens or computer integrated with the microscope.

\section{RESULTS AND FINDINGS}

\section{A. Mechanical Properties}

1) Hardness properties of sintered Al/Graphene/MWCNT hybrid composites

Table 6: Results of Hardness test carried on A16061

/Graphene/MWCNT(sintered) hybrid composites

\begin{tabular}{|c|l|c|c|c|}
\hline S/No & \multicolumn{1}{|c|}{$\begin{array}{c}\text { Alloy/ Graphene/CNT } \\
\text { Composition }\end{array}$} & $\begin{array}{c}\text { Designa } \\
\text { tion }\end{array}$ & $\begin{array}{c}\text { Hardnes } \\
\text { s } \\
\text { (BHN) }\end{array}$ & $\begin{array}{c}\text { \% } \\
\text { Improveme } \\
\text { nt } \\
\text { in Hardness }\end{array}$ \\
\hline 1 & Aluminium 6061 & $\mathrm{~A} 6061$ & 54.3 & ---- \\
\hline 2 & $\begin{array}{l}\text { Al6061 + 0.5\%CNT + 0.5\% } \\
\text { Graphene }\end{array}$ & $\mathrm{A} 1$ & 60.1 & 10.68 \\
\hline 3 & $\begin{array}{l}\text { Al6061 + 0.5\%CNT + 1\% } \\
\text { Graphene }\end{array}$ & $\mathrm{A} 2$ & 63.4 & 16.75 \\
\hline 4 & $\begin{array}{l}\text { Al } 6061+0.5 \% \mathrm{CNT}+1.5 \% \\
\text { Graphene }\end{array}$ & $\mathrm{A} 3$ & 62.8 & 15.65 \\
\hline
\end{tabular}

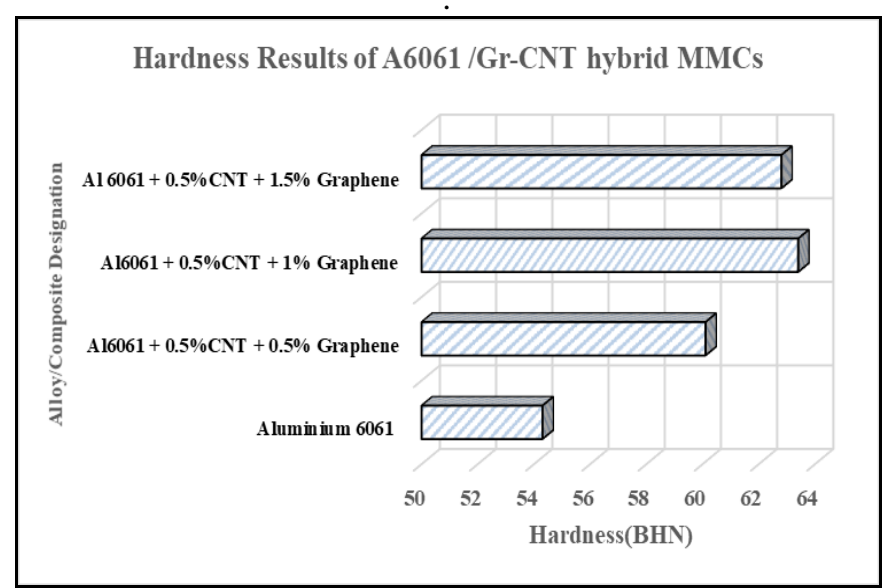

Fig 05: Hardness test results of Aluminium 6061 hybrid MMCs

Fig 05. illustrates the hardness of the hybrid MMCs of various composition. it is found that hardness increases with increase in MWCNT and graphene in the A16061 matrix material. As compared to As-Cast (6061 alloy), Al6061 + $0.5 \% \mathrm{CNT}+0.5 \%$ Graphene increase in hardness of 5.8 BHN (10.68 \%), Al6061 + 0.5\% CNT + 1\% Graphene shows an increase in hardness of $9.1 \mathrm{BHN}(16.75 \%)$ respectively, $\mathrm{Al} 6061+0.5 \% \mathrm{CNT}+1.5 \%$ Graphene shows an increase in hardness of $8.5 \mathrm{BHN}(15.65 \%)$ respectively. From the figure we can observe that as the percentage of graphene is increased there is a slight dip in hardness of hybrid composite $(\mathrm{Al} 6061+0.5 \% \mathrm{CNT}+1.5 \%)$. This may be due to agglomeration of graphene particles in A16061 + 0.5\% CNT $+1.5 \%$ hybrid composite. But overall there is improvement in hardness properties of hybrid composite compared to A6061 alloy. Similar observations were made by several researchers $[\mathbf{1 2 , 1 3}]$.

2) Mechanical properties of sintered Al/Graphene/MWCNT hybrid composites

Table 7: Results of Compression test carried on Al6061 /Graphene/MWCNT(sintered) hybrid composites

\begin{tabular}{|c|l|c|c|l|}
\hline $\begin{array}{c}\text { S/ } \\
\text { No }\end{array}$ & \multicolumn{1}{|c|}{$\begin{array}{c}\text { Alloy/ Graphene/CNT } \\
\text { Composition }\end{array}$} & $\begin{array}{c}\text { Designatio } \\
\mathbf{n}\end{array}$ & $\begin{array}{l}\text { UCS } \\
\text { (MPa } \\
\text { ) }\end{array}$ & $\begin{array}{l}\text { \% } \\
\text { Improvem } \\
\text { ent } \\
\text { in } \\
\text { compressi } \\
\text { on } \\
\text { strength }\end{array}$ \\
\hline 1 & Aluminium 6061 & A 6061 & 71.3 & ---- \\
\hline 2 & $\begin{array}{l}\text { Al6061 }+0.5 \% \mathrm{CNT}+0.5 \% \\
\text { Graphene }\end{array}$ & A1 & 75.8 & 6.31 \\
\hline 3 & $\begin{array}{l}\text { Al6061 }+0.5 \% \mathrm{CNT}+1 \% \\
\text { Graphene }\end{array}$ & A2 & 81.5 & 14.30 \\
\hline 4 & $\begin{array}{l}\text { Al } 6061+0.5 \% \mathrm{CNT}+1.5 \% \\
\text { Graphene }\end{array}$ & A3 & 79.1 & 10.93 \\
\hline
\end{tabular}




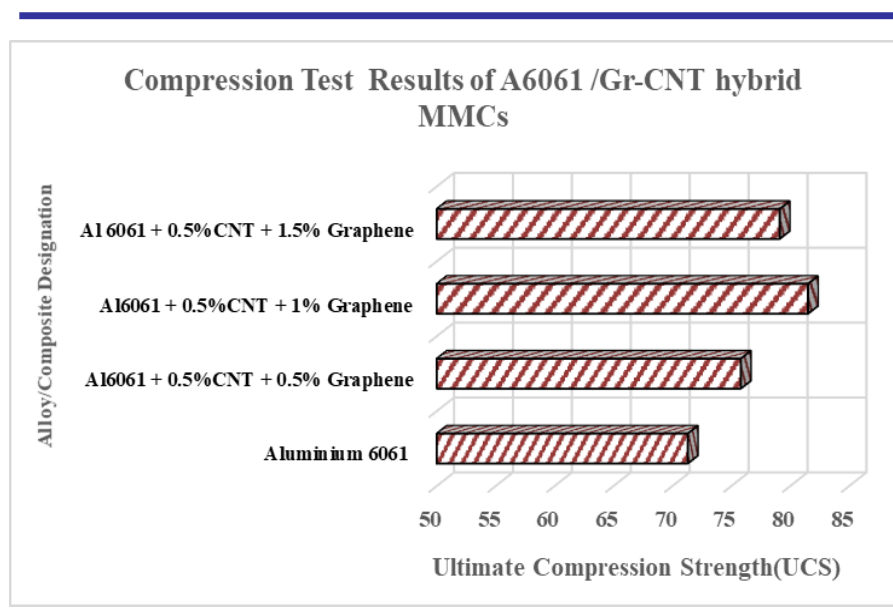

Fig 06: Ultimate Compression Strength (UCS) test results of Aluminium 6061 hybrid MMCs

Fig06. expounds the compression test results (UCS) of Aluminium 6061 hybrid MMCs after sintering process. From Figure it is found that compression strength increases with increase in MWCNT and graphene in the A16061 matrix material. As compared to As-Cast (6061 alloy), Al6061 + $0.5 \% \mathrm{CNT}+0.5 \%$ Graphene increase in compression strength of $4.5 \mathrm{MPa}(6.31 \%)$, Al6061 + 0.5\% CNT + 1\% Graphene shows an increase in compression strength of 10.2 MPa (14.30\%) respectively, Al6061 + 0.5\% CNT + 1.5\% Graphene shows an increase in compression strength of 7.8 MPa (10.93\%) respectively. From the figure we can observe that as the percentage of graphene is increased there is a slight dip in compression strength of hybrid composite $(\mathrm{Al} 6061+0.5 \% \mathrm{CNT}+1.5 \%)$. This may be due to agglomeration of graphene particles in Al6061 + 0.5\% CNT $+1.5 \%$ hybrid composite. But overall there is improvement in compression strength of hybrid composite compared to A6061 alloy.

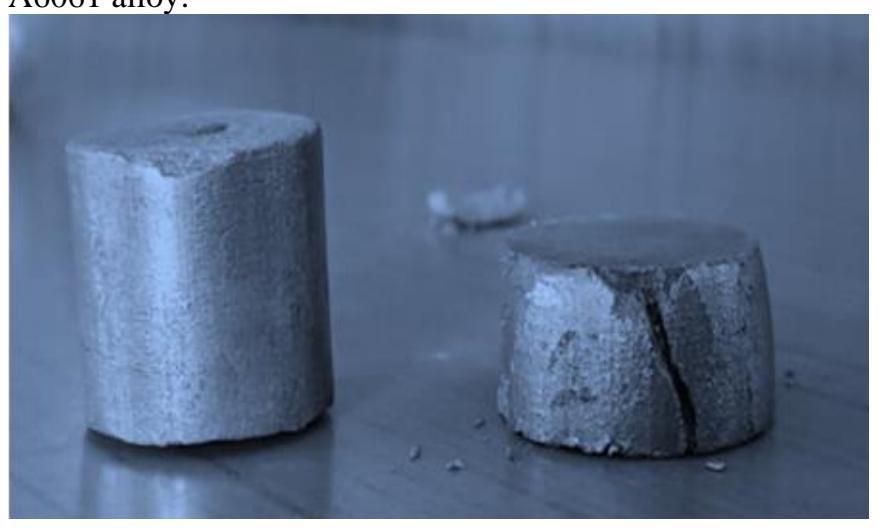

Fig 07: Comparision of specimen before and after compression test.
B. Microstructure Characterization.

1) Microstuructural Characterization by Optical Microscope.
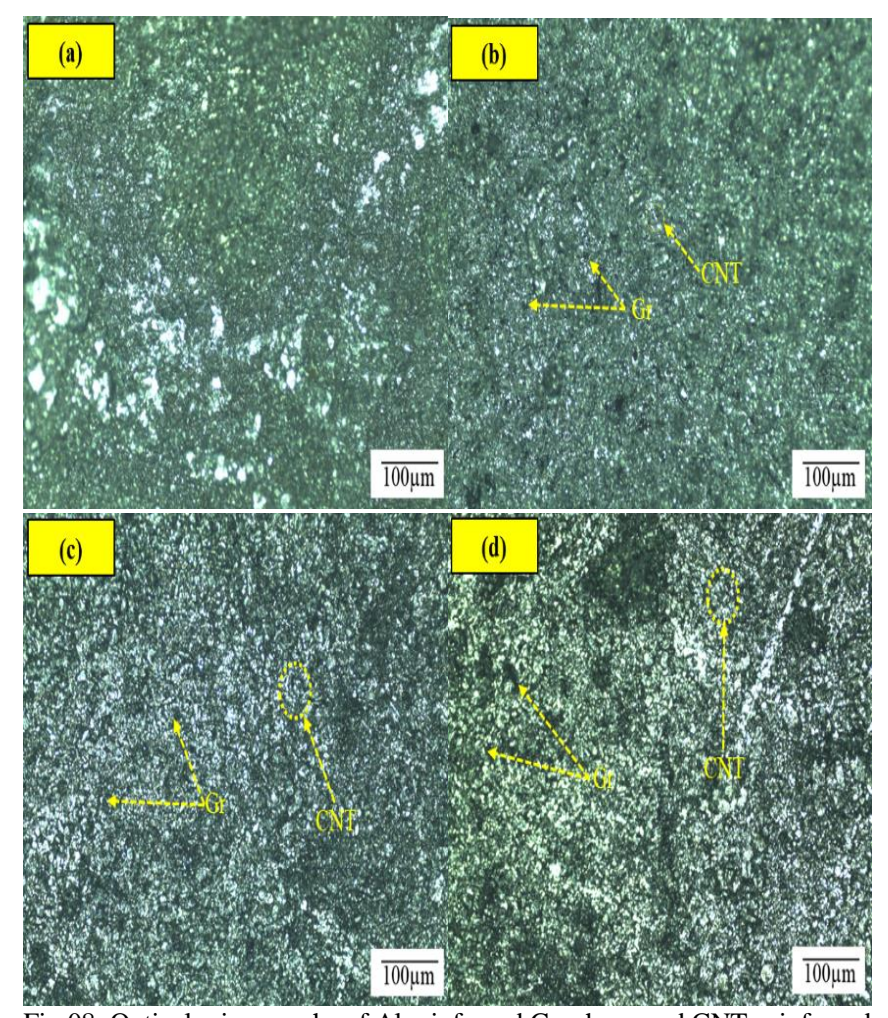

Fig 08: Optical micrographs of Al reinforced Graphene and CNT-reinforced hybrid composites where ,(a) As-cast 6061 Aluminium, (b)Aluminium $6061+0.5 \% \mathrm{CNT}+0.5 \%$ Graphene (c)Aluminium $6061+0.5 \% \mathrm{CNT}+1 \%$ Graphene (d)Aluminium 6061+0.5\%CNT $+1.5 \%$ Graphene

The above figure shows the optical micrographs of the specimens. The micrographs shows the dispersal of graphene and CNT in the aluminium 6061 matrix. Uniform distribution of the reinforcements i.e. graphene and CNT will lead to better improvement in mechanical and wear properties of the hybrid composites. The uniform dispersion of the mixture is due to the ball milling process. The graphene and CNT particles have been indicated on the micrograph.

2) Scanning electron micrograph of Al6061/Graphene/CNT (Sintered condition)

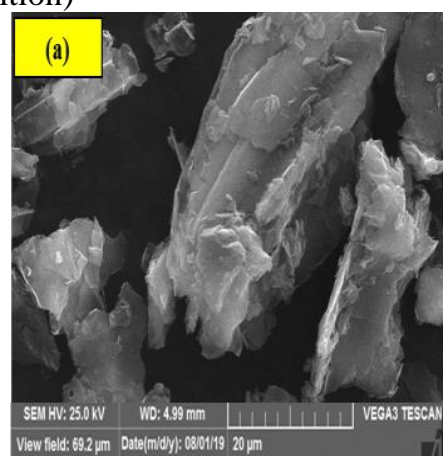



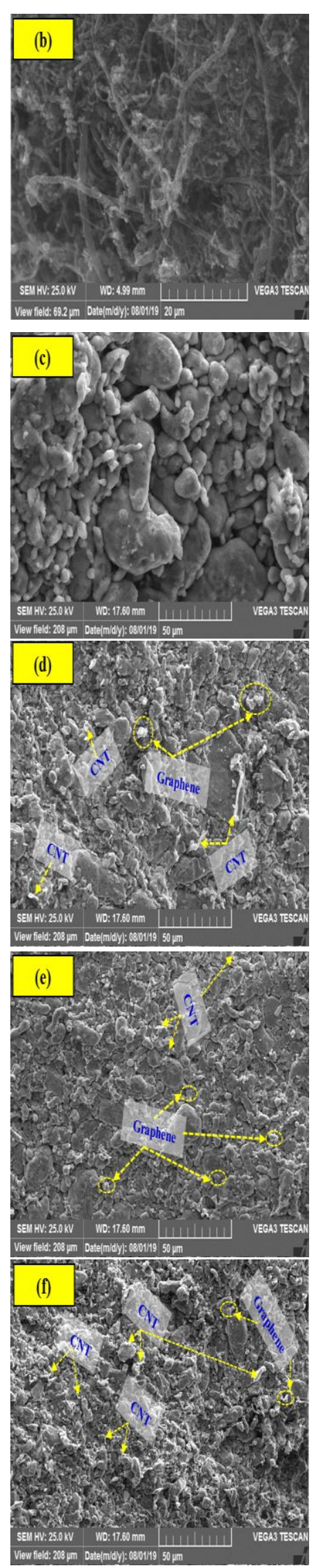
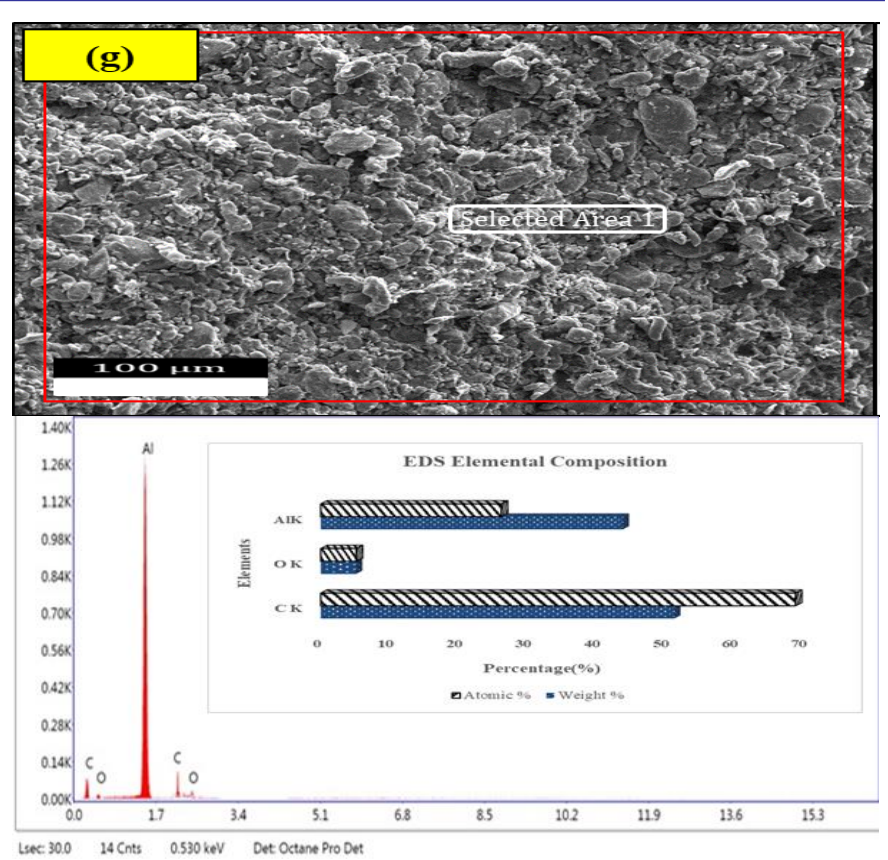

Fig 09: SEM images of Aluminium 6061 hybrid MMCs , (a) Graphene as received; (b) CNT as received; (c) as-cast Aluminium 6061; (d) Aluminium $6061+0.5 \% \mathrm{CNT}+0.5 \%$ Graphene; (e) Aluminium 6061+ 0.5\%CNT + 1\% Graphene ; (f) Aluminium 6061+ 0.5\%CNT + 1.5\% Graphene;(g) EDS analysis Aluminium $60610.5 \% \mathrm{CNT}+1.5 \%$ Graphene.

From the above SEM images we can see dispersal of graphene and CNT in the aluminium 6061 matrix. The View fields are ranging from $69 \mu \mathrm{m}$ to $208 \mu \mathrm{m}$. The CNT is shown in fig.b where the large aggloromates are formed. the large aggloromates are ranging from $20 \mu \mathrm{m}$ to several hundred micrometers. The hybrid composite showcased uniform dispersion of CNT/Graphene and exceptional interfacial bonding with the Aluminium6061. The micrographs shows a comparatively homogeneous grain size distribution for both composite materials. A homogeneous dispersion of carbon nanomaterials into the metal matrices is extremely difficult to achieve in fabricating composites because the nanoparticles tend to agglomerate into clusters during the composite processing in order to reduce their surface energy[8]. Uniform distribution of reinforcements i.e. graphene and CNT will lead to better improvement in mechanical of the hybrid composites. Fig. (f) shows the EDS analysis of aluminium $60610.5 \%$ CNT + 1.5\% Graphene. EDS analysis confirms the presence of high content of carbon (more than $70 \%$ ) in the hybrid composite. Similar observations were made by several researchers $[\mathbf{1 4 , 1 5 ]}$.

\section{CONCLUSION}

- In this study, Al6061 with CNT/Graphene Hybrid MMCs with various weight fractions of Graphene $(0.5 \%, 1 \%$, and $1.5 \%)$ were fabricated by powder metallurgy route and studied for their microstructure and mechanical properties.

- It was found that there was increase in hardness and compressive strength with increase in percentage weight of Graphene.

- There is reduction of hardness and compressive strength with increase in $1.5 \% \mathrm{wt}$ of graphene and this may be due to agglomeration of particles. 


\section{ACKNOWLEDGEMENT}

We are thankful to Department of Mechanical Engineering ,Nitte Meenakshi Institute of Technology, Bengaluru for constant encouragement and support.

\section{REFERENCES}

[1] A. K. Jha, S. V. Prasad \& G. S. Upadhyaya (1989) Preparation and Properties of 6061 Aluminium Alloy/Graphite Composites by PM Route, Powder Metallurgy, 32:4, 309-312 1.

[2] L Avinash, T Ram Prabhu, S Bontha "The Effect on the dry sliding wear behavior of gravity cast A357 reinforced with dual size siliconcarbide-particles"-Applied-Mechanics-and-Materials,829,(2016),83-89 DOI :https://doi.org/10.4028/www.scientific.net/AMM.829.83

[3] B Sajjan, L Avinash, S Varun, KN Varun Kumar, A Parthasarathy "Investigation of Mechanical Properties and Dry Sliding Wear Behaviour of Graphite Reinforced Al7068 Alloy "Applied Mechanics and Materials 867,(2017), 10-18 DOI :https://doi.org/10.4028/www.scientific.net/AMM.867.10

[4] L Avinash, T Ram Prabhu, A Parthasarathy, KN Varun Kumar, B Sajjan " Wear and mechanical behaviour of Hypo-eutectic Al-7\% Si$0.5 \% \mathrm{Mg}$ alloy (A357) reinforced with $\mathrm{Al}_{2} \mathrm{O}_{3}$ particles", Applied Mechanics and Materials ,829,(2016), 66-72 DOI: https://doi.org/10.4028/www.scientific.net/AMM.829.66

[5] A Parthasarathy, L Avinash, KN Varun Kumar, B Sajjan, S Varun "Fabrication and Characterization of $\mathrm{Al}-0.4 \% \mathrm{Si}-0.5 \% \mathrm{Mg}-\mathrm{SiCp}$ Using Permanent Mould Casting Technique "Applied Mechanics and Materials, $\quad$ 867,(2017),34-40

https://doi.org/10.4028/www.scientific.net/AMM.867.34

[6] L Avinash, H Kumar, A Parthasarathy, KN Varun Kumar, B Sajjan, "The Effect of Ceramic Reinforcement on the Microstructure, Mechanical Properties and Tribological Behavior of Al-7.5\% Si-0.5\%
Mg Alloy" Applied Mechanics and Materials, 867,(2017),3-9, https://doi.org/10.4028/www.scientific.net/AMM.867.3

[7] Avinash Lakshmikanthan, T. Ram Prabhu, Udayagiri Sai Babu, Praveennath G. Koppad, Manoj Gupta, Munishamaiah Krishna , Srikanth Bontha (2020) "The effect of heat treatment on the mechanical and tribological properties of dual size $\mathrm{SiC}$ reinforced A357 matrix composites" Journal of Materials Research and Technology, Volume 9, Issue 3, May-June 2020, Pages 6434-6452

[8] Ishtiaq Ahmed, Mohammed Shoaib Shariff, Prashanth S, Samrat Banerjee. Synthesis and Analysis of Aluminium 6063, Graphite and CNT (Hybrid) Nano Composites by using Powder Metallurgy.2018

[9] Ming-Jen Tan et al. Mixing of carbon nanotubes (CNTs) and aluminum powder for powder metallurgy use.:10.1016/j.powtec.2010.12.001

[10] Jie Teng et al. Fabrication of homogeneously dispersed graphene/Al composites by solution mixing and powder metallurgy. https://doi.org/10.1007/s12613-018-1552-4

[11] Anthony Xavior, M Prashantha Kumar H.G , Ajith Kumar.K , Tribological studies on AA 2024 -Graphene/CNT Nanocomposites processed through Powder Metallurgy. Mater. Sci. Eng. A. 2016, 667, 16-32. DOI: 10.1016/j.msea.2016.04.054.

[12] Treacy, M.; Ebbesen, T.; Gibson, J. Exceptionally High Young's Modulus Observed for Individual Carbon Nanotubes. Nature 1996, 381, 678-680. DOI: 10.1038/381678a0.

[13] Du, Z.; Li, J. Study of the Preparation of $\mathrm{Al}_{2} \mathrm{O}_{3} \mathrm{sf}-\mathrm{SiCp} / \mathrm{Al}$ Composites and Their Wear-Resisting Properties. J. Mater. Process. Technol. 2004, 151, 298-301. DOI: 10.1016/j.jmatprotec. 2004.04.077

[14] Tjong SC (2013) Recent progress in the development and properties of novel metal matrix nanocomposites reinforced with carbon nanotubes and graphene nanosheets. Mater Sci Eng R 74:281-350

[15] J.P. Tessonnier, D. Rosenthal, T.W. Hansen, C. Hess, M.E. Schuster, R. Blume, F. Girgsdies, N. P fander, O. Timpe, D.S. Su, R. Schlogl, Carbon 47 (2009) 1779- 1798 